\title{
JOB VACANCY DATA FOR DENTISTS IN AUSTRALIA: ADVERTISED VACANCIES AS AN INDICATOR OF UNMET NEED
}

\author{
Gillian Jean, Estie Kruger, Marc Tennant \\ School of Human Sciences, The University of Western Australia
}

Correspondence: gillian.jean@research.uwa.edu.au

\section{ABSTRACT}

\section{OBJECTIVES}

The aim of this study was to determine whether job vacancy data for dentists might be used as part of a needs-based index to indicate levels of workforce supply.

\section{METHODS}

Advertised job vacancies for dentists were collected at monthly intervals between October 2011 and June 2019; compiled into a data base and geo-coded by latitude and longitude. The vacancies were mapped using QGIS software and their geographic locations were observed relative to Accessibility/Remoteness Index of Australia Plus (ARIA+ 2016) and SEIFA Index of Relative Socio-economic Disadvantage (IRSD).

\section{RESULTS}

There was a slight decline in the number of advertised job vacancies relative to the population of Australia in the first 18 months of the study. For the remainder of the study period the number of vacancies per million of the population rose steadily. There were differences between ARIA+ regions; but remote and very remote Australia showed very little variation in vacancies across the study period.

The percentage of monthly advertised vacancies in IRSDI (most disadvantaged) areas was much higher (>40\%) at the start of the study period but by the end of the study the percentage of vacancies was relatively even across all IRSD groups.

\section{CONCLUSIONS}

The increase in the number of vacancies per million population since 2013 implies an increase in demand for dentists. The findings do not correlate with industry and government agency reporting of an oversupply. The use of job vacancy data might form part of a needs-based index to inform dental workforce planning.

\section{KEYWORDS}

Dentist, workforce, planning, policy, supply, Australia

\section{INTRODUCTION}

The World Health Organisation (WHO) supports and promotes a Human Rights-Based Approach (HRBA) to health service planning (Ref). Member nations are encouraged to adopt an HRBA framework to facilitate progress towards the realisation of Universal Health Coverage (UHC).[1] The HRBA is based on the four key principles of availability, accessibility, acceptability and quality. The first principle, availability, directs member nations to maintain a functioning health service built on sufficient facilities, services; and health workforce numbers to meet the needs of the population.[1] The process of estimating the number of health workers needed over time is complex and involves a dynamic process of review and reassessment of demand and supply. The WHO has developed guidelines and a code of conduct for building health workforce capacity in response to the increasing shortage of health care workers globally(COC) [2] Low and middle income nations are most keenly affected by shortages and the increase in health workforce migration 
away from these nations adds strain to under resourced health systems. The COC encourages self-sufficiency in workforce planning and discourages policy that relies on overseas recruitment of trained professionals. Historically Australia has had a high percentage of overseas trained health workers, including dentists [3-4], and more recently high numbers of international dental students who choose to remain in Australia after completing their studies.[5] Many of the overseas trained dentists that migrate to Australia originate from countries that have dentist-topopulation ratios of 3 dentists per 10000 population or less, while Australia has one of the highest dentist-to-population ratios globally.[6-7] Dental workforce planning with current methodology is known to be imprecise and despite the modelling of various demand and supply scenarios, accurate predictions remain elusive and have fostered a reliance on overseas trained personnel.[8] Demand has previously been measured on a utilisation basis that extrapolates known patterns of dental service attendance combined with demographic data on population changes, tooth retention, and disease burden.[8] The accuracy of utilisation-based modelling is dependent on the availability of comprehensive data. Medical care in Australia is subsidised through the government funded Medicare system and this permits the collection of largescale data to inform planning.[9] Conversely $95 \%$ of dental care is provided by private practitioners and only a small percentage of services receive Medicare rebates (Ref). This limits the data available for dental workforce planning. Utilisation patterns have instead been drawn from the National Dental Telephone Interview Survey 2013.[10] The design of the study, including sample size and limited disaggregation by regional area reduces the reliability of the inferences drawn.

Utilisation-based models are more likely to underestimate demand because of a frequent gap between utilisation and need.[11] The WHO promotes a transition to a "needs" based methodology that takes into account indicators of unmet need including workforce shortages in particular demographics; existing and projected morbidity, disease trends, and changes in demand for particular service items. The WHO promotes the better use and sharing of available data to develop a reliable needs-based model. Data does exist to extend the scope of demand projections for dentists. This is predominantly tightly held by custodians including private health insurance funds and individual dental practitioners. Some data is more publicly available including job vacancy data. This study analyses the job vacancy data over a 7-year period from 2011 to 2019 to see how this correlates with perceptions of workforce supply including a comparison of demand for dentists in metropolitan centres and rural and remote areas; and the distribution of job vacancies according to socio-economic indices.

\section{METHODS}

Ethics exemption: Data in this study was compiled from open access sources and ethics exemption was approved by the Human Research Ethics Office at The University of Western Australia. (Ref RA/4/20/5696)

\section{DATA}

Advertised vacancies for dentists were downloaded from a single open access web-based job advertisement site at monthly intervals between October 2011 and August 2019.[12] Details of the suburb; whether the position was offered full-time or part-time; and the date the advertisement was recorded, were compiled into a database using Excel version $16.8 \square$ Microsoft 2018.

\section{MAPPING DATA}

The latitude and longitude of the suburb centroids (geometric centre point) where vacancies were advertised were geocoded using Google maps API and mapped using geographical imaging software (QGIS v3.4.0-Madeira licenced under the GNU Public Licence http://www.gnu.org/licences). Geographic census district boundaries and remoteness classification boundaries (Accessibility/Remoteness Index of Australia Plus - ARIA+ 2016) were added to the mapping using data downloaded from the Australian Bureau of Statistics (ABS).[13]

\section{POPULATION DATA}

The Socio-economic Index for Areas (SEIFA) published by the ABS aggregates markers of economic advantage and disadvantage including household income and unemployment rates; housing details; and level of education, based on information collected at each population census.[14] One of the four SEIFA indices, the Index of Relative Socio-economic Disadvantage (SEIFAIRSD) was used to classify Statistical Area 1 (SA 1) census districts into 5 equal groups. SEIFA-IRSD1 most disadvantaged to SEIFA-IRSD5 least disadvantaged.

\footnotetext{
ANALYSIS

QGIS computed the location of advertised vacancies according to SEIFA - IRSD and ARIA+ and the results were exported to R Studio (version 1.1.456 - (c) 2009 - 2018 RStudio,
} 
Inc) for final analysis. 24 months were missing from the full data set. Time series imputation for missing values of advertised vacancies, for each SEIFA-IRSD and ARIA+, was conducted using imputeTS software and the Kalman Smoothing algorithm to permit year by year comparisons.[15]

\section{RESULTS}

The details of a total of 14104 advertised vacancies for dentists were compiled between October 2011 and June
2019. Almost two-thirds (64\%) of all vacancies were for positions in ARIA+ major cities; $23 \%$ in inner regional: $11 \%$ in outer regional; $1 \%$ in remote and $0.3 \%$ in very remote areas (Figure 1). A total of $43 \%$ of vacancies were for full-time employment; $49 \%$ for part-time employment and $8 \%$ for either casual, locum, or volunteer roles. The overall number of vacancies advertised each month increased across the study time frame in major cities and inner and outer regional areas (Table 1). The number of vacancies in remote and very remote areas were too few to permit time series imputation analysis and were excluded from the mean monthly average tables by ARIA+.

FIGURE 1: ALL DENTIST JOB VACANCIES BY ACCESSIBILITY/REMOTENESS INDEX FOR AUSTRALIA PLUS (ARIA+) - NO IMPUTED VALUES.

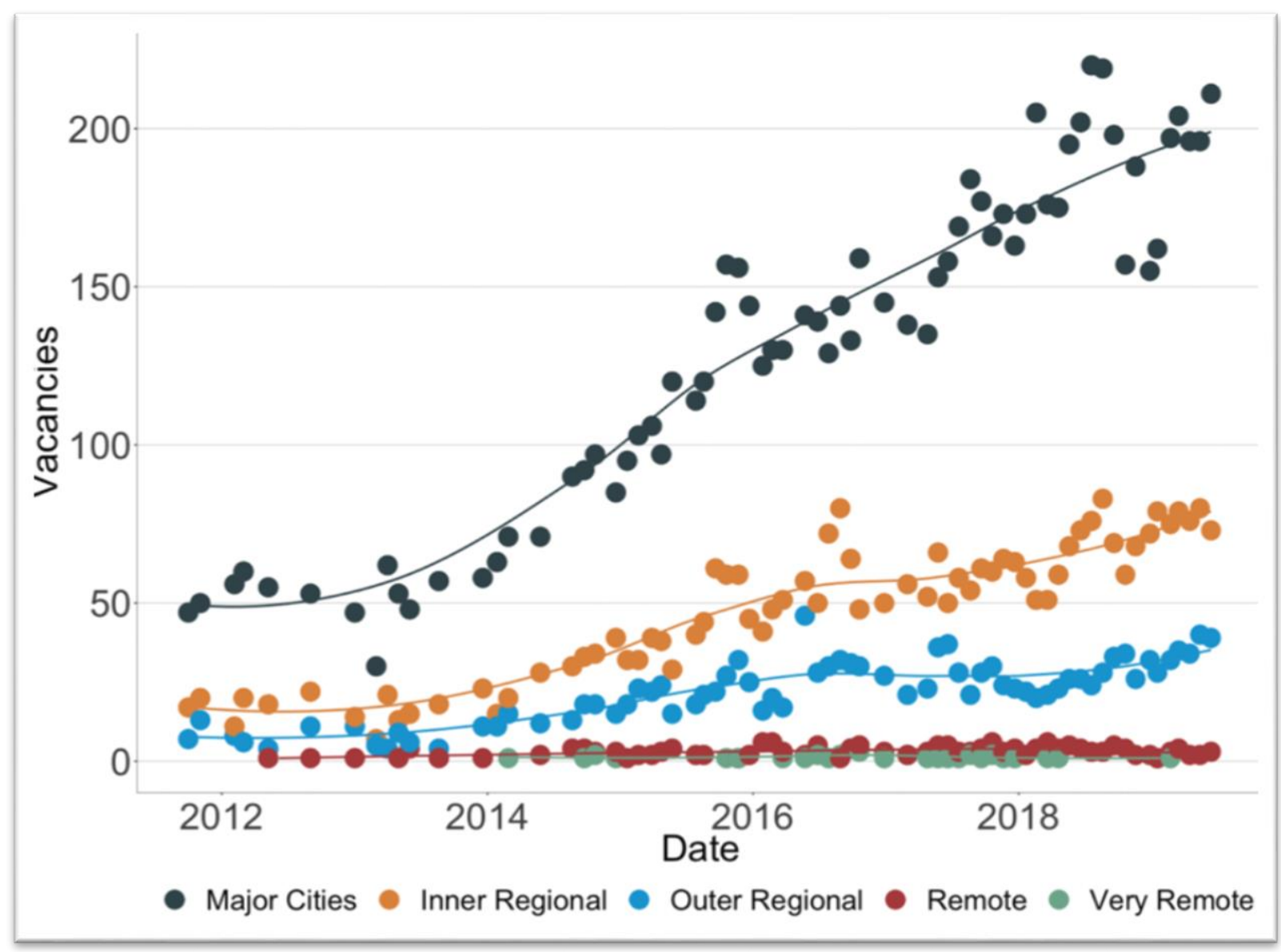


TABLE 1. MEAN (SD) MONTHLY ADVERTISED VACANCIES FOR ALL STATES AND TERRITORIES OF AUSTRALIA BY ACCESSIBILITY/REMOTENESS INDEX FOR AUSTRALIA PLUS (ARIA+) EXCLUDING REMOTE AND VERY REMOTE AREAS.

\begin{tabular}{|c|c|c|c|}
\hline \multicolumn{4}{|c|}{ ARIA+ classification } \\
\hline Year & Major Cities & Inner Regional & Outer Regional \\
\hline \multicolumn{4}{|c|}{ Full Time } \\
\hline 2011 & $12.7(2.1)$ & $12.4(1.5)$ & $6.7(2.1)$ \\
\hline 2012 & $17.1(2.4)$ & $12.1(0.8)$ & $6.7(1.4)$ \\
\hline 2013 & $15.8(4.8)$ & $11.4(2.6)$ & $6.0(2.4)$ \\
\hline 2014 & $23.8(4.8)$ & $17.6(5.9)$ & $10.6(1.6)$ \\
\hline 2015 & $37.3(7.7)$ & $28.7(8.5)$ & $15.4(3.8)$ \\
\hline 2016 & $42.9(6.1)$ & $32.9(4.5)$ & $19.4(5.4)$ \\
\hline 2017 & $46.8(6.3)$ & $34.7(2.9)$ & $20.3(4.0)$ \\
\hline 2018 & $54.3(8.6)$ & $42.0(6.7)$ & $20.7(4.6)$ \\
\hline 2019 & $48.3(4.3)$ & $53.3(3.9)$ & $27.7(3.1)$ \\
\hline \multicolumn{4}{|c|}{ Part Time } \\
\hline 2011 & $33.8(0.7)$ & $4.3(0.6)$ & $0.4(0.5)$ \\
\hline 2012 & $33.5(2.6)$ & $4.0(1.4)$ & $0.2(0.2)$ \\
\hline 2013 & $32.9(5.2)$ & $3.6(1.4)$ & $1.3(0.4)$ \\
\hline 2014 & $49.6(6.9)$ & $7.2(1.1)$ & $1.7(0.9)$ \\
\hline 2015 & $73.3(12.4)$ & $11.2(3.2)$ & $5.0(1.7)$ \\
\hline 2016 & $81.8(7.1)$ & $18.3(7.0)$ & $4.7(2.0)$ \\
\hline 2017 & $100.6(16.5)$ & $18.3(4.1)$ & $5.1(1.6)$ \\
\hline 2018 & $120.8(13.0)$ & $20.8(4.3)$ & $5.3(2.1)$ \\
\hline 2019 & $130.3(12.8)$ & $20.2(2.8)$ & $5.0(2.0)$ \\
\hline
\end{tabular}

A comparison of vacancies relative to the population showed that the rate per million both for full-time and parttime vacancies more than tripled between 2011 and 2019 (Figure 2).

The majority of vacancies were in the major population centres, but relative to the population, the number of fulltime job vacancies was consistently higher in outer regional areas and the number of vacancies in major cities was consistently lower than for inner regional areas (Figure 3).
Part-time vacancies were highest per capita in major cities and lowest in outer regional areas. The mean monthly average of advertised vacancies relative to the SEIFA-IRSD, increased year by year with the exception of 2013, and there were fluctuating values for full-time positions in the least disadvantaged SEIFA-IRSD 5 group (Table 2).

There were consistently more vacancies in the most disadvantaged areas although the percentage of the total monthly vacancies by IRSD changed over time (Figure 4). 
In the final 18 months of the study there was a noticeable steady decline in the percentage of vacancies in IRSDI and IRSD2 areas, matched by a steady increase in IRSD 4 and IRSD 5 districts.

FIGURE 2. ADVERTISED VACANCIES FOR DENTISTS RELATIVE TO THE POPULATION OF AUSTRALIA.

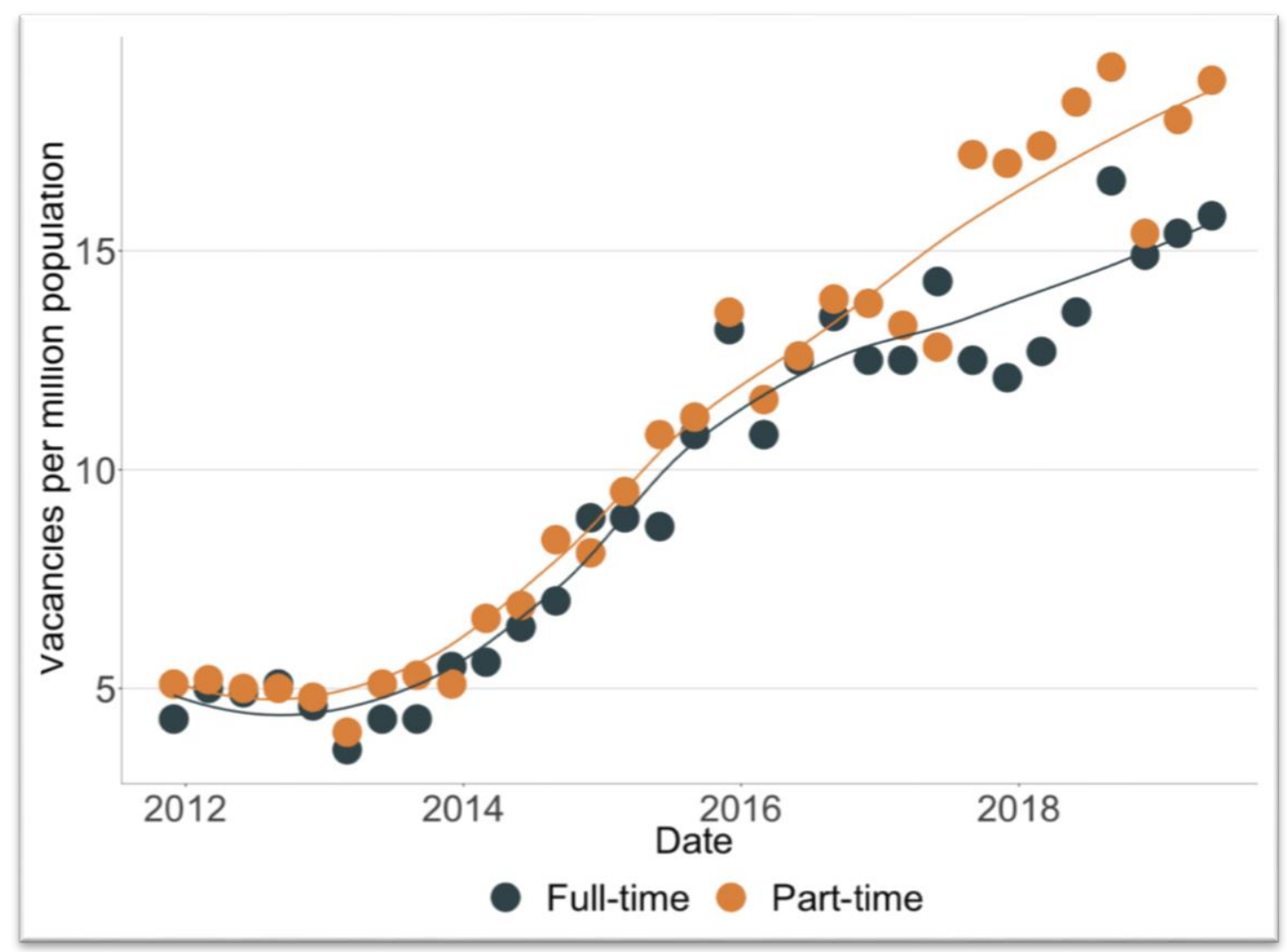

FIGURE 3. ADVERTISED VACANCIES FOR DENTISTS RELATIVE TO THE POPULATION OF AUSTRALIA CLASSIFIED BY ARIA+, EXCLUDING REMOTE AND VERY REMOTE AREAS

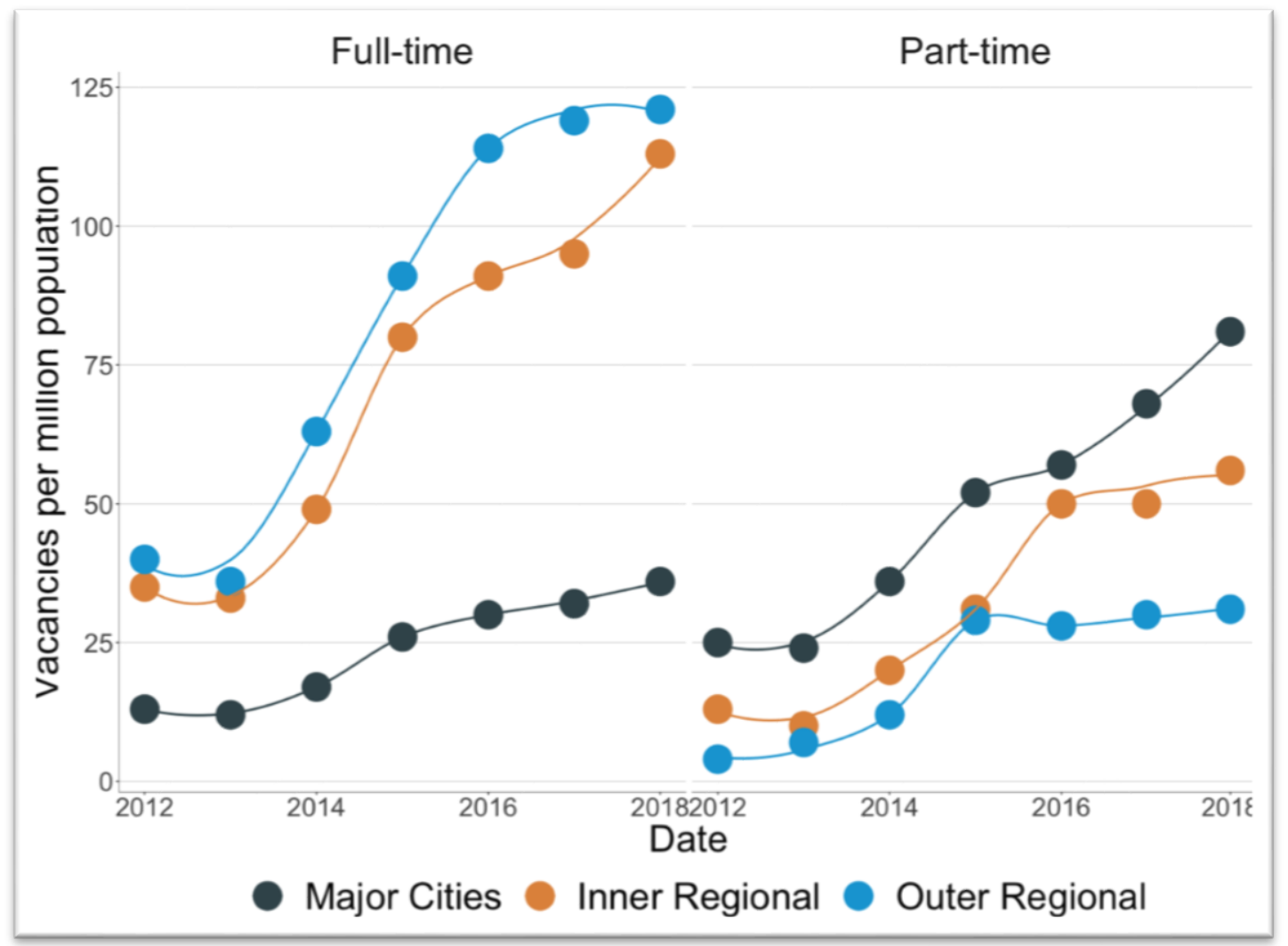


TABLE 2. MEAN (SD) MONTHLY ADVERTISED VACANCIES FOR DENTISTS ACROSS ALL STATES AND TERRITORIES OF AUSTRALIA (EXCLUDING ADVERTISED VACANCIES FOR REMOTE AND VERY REMOTE AREAS) BY SOCIO-ECONOMIC INDEX FOR AREAS (SEIFA) INDEX OF RELATIVE SOCIO-ECONOMIC DISADVANTAGE (SEIFA-IRSD1 - MOST DISADVANTAGED, SEIFA-IRSD5 LEAST DISADVANTAGED)

\begin{tabular}{|c|c|c|c|c|c|c|}
\hline & SEIFA & & & & & \\
\hline YEAR & IRSD1 & IRSD2 & IRSD3 & IRSD4 & IRSD5 & NO IRSD \\
\hline $\begin{array}{l}\text { FULL } \\
\text { TIME }\end{array}$ & & & & & & \\
\hline 2011 & $12.7(2.5)$ & $8.9(1.2)$ & $6.2(1.1)$ & $1.3(1.4)$ & $1.9(.8)$ & $1.0(0.0)$ \\
\hline 2012 & $13.1(1.3)$ & $5.0(1.4)$ & $8.6(1.3)$ & $4.8(1.9)$ & $3.5(1.3)$ & $1.1(0.4)$ \\
\hline 2013 & $9.5(2.2)$ & $7.2(2.4)$ & $6.8(2.2)$ & $3.5(1.5)$ & $4.4(1.7)$ & $1.6(0.9)$ \\
\hline 2014 & $17.5(4.7)$ & $14.2(5.5)$ & $7.5(2.7)$ & $5.0(2.0)$ & $4.9(0.8)$ & $3.7(1.8)$ \\
\hline 2015 & $28.2(6.3)$ & $21.0(5.1)$ & $12.9(4.1)$ & $5.5(2.4)$ & $7.6(3.3)$ & $5.8(2.3)$ \\
\hline 2016 & $28.9(5.7)$ & $22.3(2.7)$ & $21.3(6.8)$ & $9.2(4.0)$ & $7.0(2.5)$ & $6.6(2.7)$ \\
\hline 2017 & $39.1(7.9)$ & $24.5(4.3)$ & $17.8(4.6)$ & $8.0(2.1)$ & $6.1(3.4)$ & $6.2(2.0)$ \\
\hline 2018 & $39.8(6.6)$ & $28.3(4.8)$ & $24.3(5.4)$ & $10.3(4.6)$ & $6.4(4.5)$ & $7.9(2.3)$ \\
\hline 2019 & $40.5(4.2)$ & $28.8(1.8)$ & $24.7(4.6)$ & $18.2(2.1)$ & $11.5(1.9)$ & $5.7(3.1)$ \\
\hline $\begin{array}{l}\text { PART } \\
\text { TIME }\end{array}$ & & & & & & \\
\hline 2011 & $17.3(1.6)$ & $5.8(2.6)$ & $6.7(0.6)$ & $3.2(1.6)$ & $3.8(1.0)$ & $1.4(1.3)$ \\
\hline 2012 & $12.0(2.8)$ & $7.2(1.8)$ & $7.5(0.9)$ & $3.7(1.7)$ & $3.9(1.1)$ & $2.8(1.1)$ \\
\hline 2013 & $8.6(2.4)$ & $8.9(2.3)$ & $6.5(1.0)$ & $4.9(2.3)$ & $5.9(1.8)$ & $3.3(1.2)$ \\
\hline 2014 & $13.8(4.3)$ & $13.5(3.3)$ & $10.6(4.3)$ & $8.0(1.8)$ & $8.2(1.7)$ & $4.7(1.4)$ \\
\hline 2015 & $23.4(6.1)$ & $20.5(4.0)$ & $15.3(2.4)$ & $12.2(2.3)$ & $11.5(4.4)$ & $6.6(4.2)$ \\
\hline 2016 & $22.0(4.0)$ & $24.5(2.7)$ & $21.4(4.0)$ & $16.0(3.3)$ & $14.9(3.0)$ & $6.1(1.6)$ \\
\hline 2017 & $32.0(11.2)$ & $28.7(6.9)$ & $24.8(5.3)$ & $19.7(2.7)$ & $11.4(3.6)$ & $7.4(1.2)$ \\
\hline 2018 & $38.3(7.0)$ & $30.4(8.4)$ & $26.8(3.4)$ & $23.0(4.7)$ & 18.3(3.0) & $10.0(3.9)$ \\
\hline 2019 & $30.0(4.5)$ & $24.5(4.9)$ & $31.8(2.6)$ & $31.5(5.5)$ & $26.8(6.4)$ & $10.8(3.2)$ \\
\hline
\end{tabular}




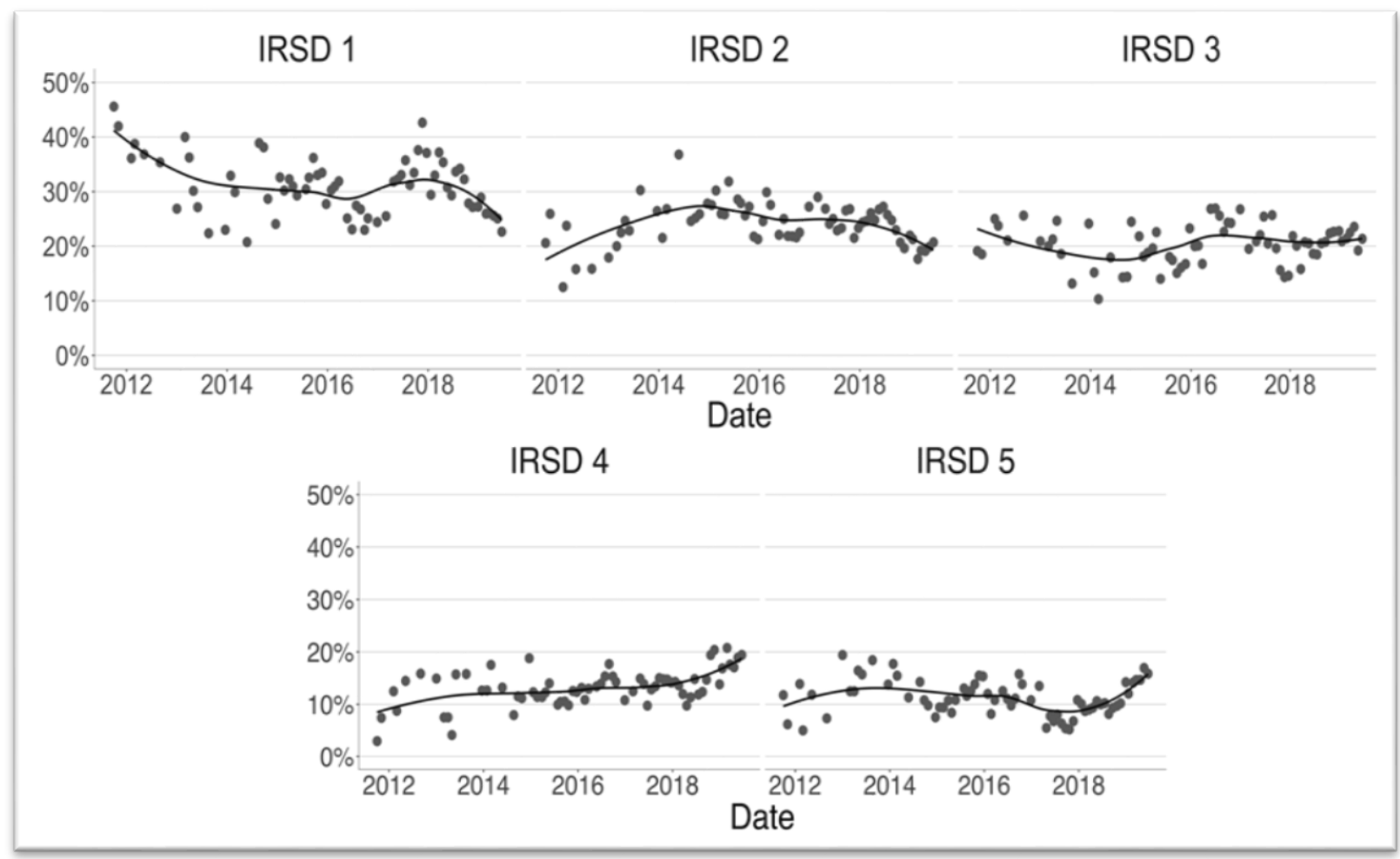

\section{DISCUSSION}

The results imply that the demand for dentists continues to be strong and that current perceptions of an oversupply may be unfounded. The continued growth in the number of vacancies relative to the population is a strong indicator that inflow to the profession is not outpacing demand. 2013 was the only year that recorded a decrease in advertised job vacancies. This correlated with the sharp increase in local graduate numbers due to the first final year course completion at new dental schools.[16] The demand for fulltime dentists is lower per capita in major cities relative to inner and outer regional areas, but demand is growing and will be sustained by steady population growth (Figure 3). The consistently higher number of part-time roles relative to full-time roles in major cities has been interpreted as an indication that there are fewer employment opportunities (Figure 3).[17] This might also reflect a change in work patterns. There is evidence of a preference for part-time work; there are more applicants for part-time than full-time roles, and full-time roles are more likely to remain unfilled.[18]

Historically it has been difficult to attract and retain dentists to regional Australia.[19] The steep rise in advertised vacancies in inner and outer regional areas might imply that over the past 6 years it has become harder to recruit in these districts and indicate unmet need. The results warrant further comparison to changes in the distribution of dental practices. It is possible that a growth of new practices in previously underserviced centres is driving demand for dentists in these areas. [20-22]

The time taken to fill advertised vacancies might offer a better indication of unmet need than the collection of the number of vacancies alone. There has been a rise in the number of practices under corporate ownership and a consequent increase in opportunities for those seeking to practice in an employee relationship.[20] The limited available data for dentists reports no change in "time to fill" since 2010. [18] This might infer that the higher relative numbers of vacancies do not reflect a reluctance of dentists to engage in employee arrangements or indicate a burgeoning unmet need. Rather, a rise in demand for dental services that is currently balanced by a rise in the number of registered dentists. The use of "time to fill" for data would be an important element of a needs-based index for workforce planning. 
Vacancy data has previously been excluded from workforce modelling in Australia because there is no agreed vacancy rate that reflects a workforce shortage; advertised vacancies may reflect difficulty in recruiting to certain demographics rather than a workforce undersupply; and vacancy rates may not indicate a true level of undersupply since they do not capture areas that are totally lacking in services.[8] This study indicates that vacancy data can offer insights into the state of the sector and that the concerns raised can be addressed by careful consideration of how the data is collected and interpreted. Vacancy data has been used to inform demand modelling elsewhere and the WHO supports the use of workforce data, including job vacancy data, as part of improved strategies to align demand estimates to better account for rural workforce disparities.[1 1] In Finland, dental workforce planning is broken down to a municipal level and vacancy rates are used to assess the number of areas where shortages persist. The Netherlands use vacancy rates and distribution of GPs (not dentists) in rural areas to measure unmet need.[23] A similar approach could form part of a local needs-based demand methodology and collect and monitor job vacancies by state and territory and ARIA+. Denmark records vacancies in public sector roles and uses this as a minimum estimate of undersupply.[23] The latter is an area that has relevance locally. Australia's National Oral Health Plan 2015 - 2024 cites ongoing difficulties in recruiting dentists to work in public sector roles as a barrier to maximising efficiency in service provision.[24] The public dental service in Australia is a minor employer of dentists and uncompetitive salaries reduce the appeal of employment.[24] A recent Grattan Institute report addressing the oral health care needs of financially disadvantaged populations, proposed a $20 \%$ expansion of public dental services and estimated that the current capacity of the dental workforce was such that it could absorb this expansion.[25] The number of vacancies recorded would imply otherwise, but closer monitoring of advertised public sector vacancies and time to fill data might be used effectively to inform planning.

Job vacancy data for healthcare workers is also considered to be a strong indicator of demand levels because the health sector is not as sensitive to economic conditions as other employment areas. [23] In many sectors of industry, a falling number of monthly job vacancies is an early indicator of slowing economic growth and conversely a rising number of advertisements is synonymous with economic recovery. Rates published by Trading Economics on behalf of the Australia and New Zealand Banking group show a marked decline in advertised vacancies across all industries, in the 18 months to June 2019.[26] This decline is not mirrored by the findings of this study and vacancy rates for dentists have continued to rise. This is despite the fact that many Australians postpone regular dental care because of financial hardship, [25] and that the current economic downturn and higher unemployment would be expected to push attendance rates lower. The fact that this is not reflected in dentist job vacancy data implies that there is continuing strong demand.

\section{STRENGTHS AND LIMITATIONS}

The study compiled a database of all the vacancies listed at monthly intervals. The web site chosen for this study retained listings for 3 months unless taken down by the advertiser. It was noted that corporate advertisers refreshed their posts regularly to retain their position near the top of the search results. It was not possible to clearly differentiate between new corporate listings and readvertisement of unfilled corporate vacancies. Vacancies in sought after locations might also be listed for very short time frames and not be captured consistently by monthly data collections. It is possible that the method of collection in this study under reported vacancies in some areas.

The study focused on the vacancies posted on a single web site to avoid duplication of observations. A comparison of advertised vacancies for a single 30-day period across 4 major employment web sites indicated that the majority of vacancies are advertised on multiple but not all online platforms.[12,27-29] Elimination of duplicates is problematic because of the variation in formatting between web sites. The Australian Government Labour Information IVI reports include all new listings across 3 employment sites and do not attempt to remove duplicates. This method allows generalised month by month comparisons without the more detailed regional and socio-economic analysis sought by this study.[30]

Having considered these limitations, it was decided to include all advertisements listed at each collection date on a single web site as a reasonably accurate reflection of available vacancies.

\section{CONCLUSION}

Job vacancy advertisements for dentists per million of the population rose for six consecutive years between 2013 and 2019, and the rise was most pronounced in outer 
regional areas of Australia. There was also a steady rise in advertised vacancies in Australian major cities. The demand for dentists as shown by job vacancy data does not correlate with current perceptions of workforce oversupply and would seem to imply unmet need. The findings of this study indicate that there might be benefits to including data on job vacancies as part of a needsbased index to project required dental workforce numbers. Job vacancy data is publicly available; updated monthly; easily analysable to monitor regional and socio-economic differences and can provide a dynamic indicator to better inform dental workforce planning. Stronger dental workforce projections will benefit Australia; allow it align workforce planning with WHO guidelines; and reduce reliance on overseas trained personnel.

\section{DECLARATION OF CONFLICTING INTERESTS:}

The Authors declare that there is no conflict of interest.

\section{References}

1. London L. What is a Human-Rights Based Approach to Health, and Does It Matter? Health Hum Rights 2008;10(1):65-80.

2. World Health Organisation. The WHO Global Code of Practice on the International Recruitment of Health Personnel. 2010.

3. National Advisory Council on Dental Health. Report of the National Advisory Council on Dental Health.2012. Available: https://www1.health.gov.au/internet/publications/pu blishing.nsf/Content/report_nacdh report_nacdh_exe c (Accessed 23/03/2020)

4. Balasubramanian M, Spencer AJ, Short SD, Watkins K, Chrisopoulos S, Brennan DS. Characteristics and practice profiles of migrant dentist groups in Australia: implications for dental workforce policy and planning. Int Dent J. 2015;65:145-55

5. Australian Institute of Health and Welfare(AlHW). Dental workforce 2012. Canberra: AlHW;2012.

6. GHO | By category | Dentistry personnel. WHO. Available: <http://apps.who.int/gho/data/node.main.HWFGRP_0 060? lang=en $>$ (Accessed 2/09/2019)

7. Australian Dental Council. Annual Report 2017/2018. Melbourne; 2018. Available:

<https://www.adc.org.au/sites/default/files/Media_Lib
raries/Corporate_documents/ADC_2017_2018_Annual _Report_FINAL.pdf> (Accessed 8/08/2019)

8. Health Workforce Australia. Australia's Future Health Workforce - Oral Health - Detailed Report. Canberra: Department of Health; 2014.

9. Crettenden IF, McCarty MV, Fenech BJ, Heywood T, Taitz MC, Tudman S. How evidence-based workforce planning in Australia is informing policy development in the retention and distribution of the health workforce. Hum Resour Health 2014 Dec;12(1):1-13.

10. National Dental Telephone Interview Survey 2013. Available:

<https://meteor.aihw.gov.au/content/index.phtml/ite $\mathrm{mld} / 629709>$ (Accessed 2/09/2019)

11. Executive Board 138. Global Strategy on human resources for health: workforce 2030: draft resolution proposed by Norway, South Africa, Switzerland, Thailand, United States of America, Zambia,

Zimbabwe and European Union Member States. 2016. Available:

<https://apps.who.int/iris/handle/10665/250763> (Accessed 25/07/2019)

12. Australian Dental Association. Careers in Dentistry/Jobs Board. Available: <https://www.ada.org.au/Careers/Jobs-Board> (Accessed 2/09/2019)

13. Australian Bureau of Statistics. Australian Government 2019. Available: <https://www.abs.gov.au/> (Accessed 15/05/2019)

14. Australian Bureau of Statistics. Socio-economic Indexes for Areas (SEIFA). Canberra: Australian Bureau of Statistics; 2013 Mar. Report No.: ABS Catalogue no. 2033.0.55.001. Available:

<http://www.abs.gov.au/ausstats/abs@.nsf/Lookup/20 33.0.55.001 main+features52011> (Accessed $17 / 10 / 2019)$

15. Moritz S, Bartz-Beielstein T. imputeTS: Time Series Missing Value Imputation in R 2017. Epub ahead of print 2017. DOI: 10.32614/rj-2017-009.

16. Chrisopoulos S, Teusner D. Dentist labour force projections 2005 to 2020: The impact of new regional dental schools. Aust Dent J. 2008 Oct 1;53:292-6.

17. Department of Employment S. 0048 Australian Dental Association | Department of Employment, Skills, Small and Family Business - Document library, Australian Government 2017. Available: 
<https://docs.employment.gov.au/0048-australiandental-association> (Accessed 5/09/2019)

18. Department of Employment. Dentist - Current Labour Market Rating - Report No.: ANZSCO 2523-12. Canberra: Australian Government; 2017.

19. Report of the National Advisory Council on Dental Health. Canberra: Australian Government; 2012.

20. Holden ACL. Consumer-driven and commercialised practice in dentistry: an ethical and professional problem? Med Health Care Philos Epub ahead of print 20 March 2018. DOI: 10.1007/s1 1019018-9834-1.

21. Shiikha Y, Kruger E, Tennant M. Rural and remote dental services shortages: filling the gaps through geospatial analysis evidence-based targeting. Health Inf Manag J 2015;44(3):39-44.

22. Ahern S, Woods N, Kalmus O, Birch S, Listl S. Needsbased planning for the oral health workforce development and application of a simulation model. Hum Resour Health.2019;17(1):55.

23. Ono T, Lafortune G, Schoenstein M. Health Workforce Planning in OECD Countries- A Review of 26 Projection Models from 18 Countries. Paris: OECD; 2013.

24. Oral Health Monitoring Group: Community Care and Population Health Principal Committee. Australia's National Oral Health Plan 2015-2014. Canberra: Australian Government; 2015.

25. Duckett S, Cowgill M, Swerissen H. Filling the gap: A universal dental care scheme for Australia. Grattan Institute 2019. Available:

<https://grattan.edu.au/report/filling-the-gap/> (Accessed 29/05/2019)

26. Australia Job Vacancies | 2019 | Data | Chart | Calendar | Forecast | News. Available: <https://tradingeconomics.com/australia/jobvacancies> (Accessed 2/09/2019)

27. Career One. Job Search - Dentists. Available:< https://www.careerone.com.au/ > (Accessed 15/01/2019)

28. Indeed. Job Search | Dentist. [cited 2020 Jan 15]. Available: <https://au.indeed.com/?from=gnavjobsearch--jasx> (Accessed 15/01/2019)
29. Seek. SEEK - Australia's no. 1 jobs, employment, career and recruitment site SEEK. Available: <https://www.seek.com.au/> (Accessed 15/01/2019) 30. Welcome to the Labour Market Information Portal. Available from: <http://Imip.gov.au/default.aspx?LMIP/Gainlnsights/V acancyReport> (Accessed 13/09/2019) 